\title{
Is fasting necessary before prilocaine Bier's block?
}

Íomhar O’Sullivan, Sue Brooks, Jalal Maryosh

\begin{abstract}
Objective-To determine whether fasting is necessary before intravenous regional anaesthesia (Bier's block).

Methods-A questionnaire study was carried out to assess accident and emergency (A\&E) departments' policies and opinions in relation to Bier's block anaesthesia. Questionnaires were sent to 282 A\&E consultants, of whom 216 replied ( $77 \%$ response rate).

Results-About 5000 Bier's block procedures are carried out each year in the United Kingdom. Intravenous regional anaesthesia appears safe. Over one third of units did not fast their patients. The complication rate was similar in fasted and unfasted groups.

Conclusions-Starvation of the patient before intravenous regional anaesthesia is not necessary and should be abandoned. ( $\mathcal{F}$ Accid Emerg Med 1996;13:105-107)
\end{abstract}

Key terms: Bier's block; fasting; prilocaine; complication rate
Biers block - intravenous regional anaesthesia (IVRA) - is frequently used in accident and emergency (A\&E) departments in the United Kingdom. Some textbooks advise fasting patients beforehand. The Royal College of Anaesthetists offers no specific additional guidelines. We conducted a questionnaire survey of $A \& E$ departments, asking about their policies and complication experience.

\section{Methods}

In March 1994, our questionnaire (fig 1) was sent to each $A \& E$ director. After one month, a further copy was sent to each nonrespondent. The returns were processed in a confidential manner and results were analysed using the EPI6 program.

\section{Results}

Of 282 consultants contacted, 216 replied ( $77 \%$ response rate); 10 replies were disregarded on account of the specialist nature of the $A \& E$ units concerned (that is, those specialising in minor injuries, ophthalmological emergencies, or paediatrics). A further four
Kent and Canterbury Hospital,

Ethelbert Road,

Canterbury,

Kent CT1 3NG,

United Kingdom

Í O'Sullivan

$S$ Brooks

J Maryosh

Correspondence to:

Î O'Sullivan, Senior Registrar in $\mathrm{A} / \mathrm{E}$ Medicine

\section{ANAESTHETIC PROCEDURES USED IN MANIPULATION OF CLOSED FRACTURES DISTAL RADIUS}

COMMONEST TYPE OF ANAESTHETIC PROCEDURE USED:

HAEMATOMA BLOCK

GENERAL ANAESTHETIC

BIERS BLOCK

NO YES

IF BIERS BLOCK, (CITANEST)

OTHERS (PLEASE SPECIFY)

IF PRILOCAINE (CITANEST) BIERS BLOCK

IS IT PERFORMEO BY

ANAESTHETIC STAFF

A \&. E STAFF

OTHERS (PLEASE SPECIFY)

WHAT VOLUME OF ANAESTHETIC USEO

ANY SUPPLEMENTAL SEDATION I ANALGESIA USED NO YES

IF YES PLEASE SPECIFY

EQUIPMENT USED

MANUAL CUFF (BICYCLE PUMP)

AUTOMATIC CUFF

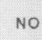

OTHERS (PLEASE SPECIFY)

CUFF PADDING USED

no

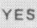

NO

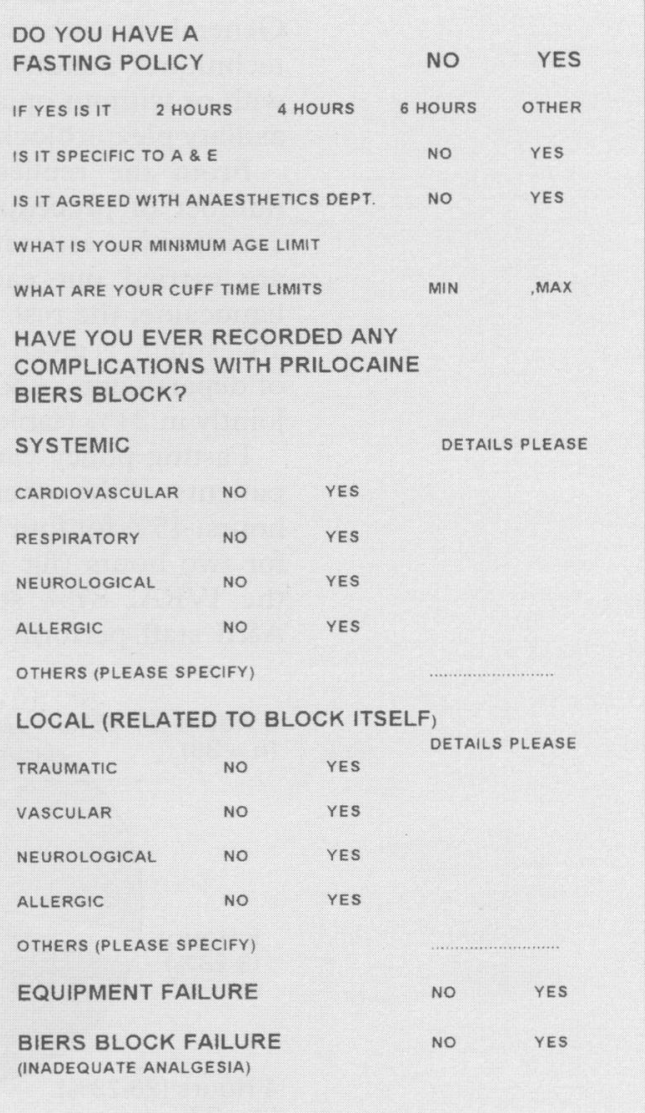

Figure 1 The questionnaire 


\begin{tabular}{llll}
\hline & Who does the Bier's block? $(n=122$ responses) & \\
\cline { 2 - 4 } & $\begin{array}{l}\text { AEE staff only } \\
(n=43)\end{array}$ & $\begin{array}{l}\text { Anaesthetic staff } \\
\text { only } \\
(n=54)\end{array}$ & $\begin{array}{l}\text { A EEE, anaesthetic staff } \\
\text { jointly } \\
(n=25)\end{array}$ \\
\hline $\begin{array}{l}\text { Have a fasting policy }(\mathrm{n}=71) 58 \% \\
\text { Ever had complications }(\mathrm{n}=23) 19 \%\end{array}$ & $\begin{array}{l}26 \%(\mathrm{n}=11) \\
14 \%(\mathrm{n}=6)\end{array}$ & $\begin{array}{l}85 \%(\mathrm{n}=46) \\
22 \%(\mathrm{n}=12)\end{array}$ & $\begin{array}{l}56 \%(\mathrm{n}=14) \\
20 \%(\mathrm{n}=5)\end{array}$ \\
Added IV sedation/analgesia $(\mathrm{n}=21) 17 \%$ & $12 \%(\mathrm{n}=5)$ & $22 \%(\mathrm{n}=12)$ & $16 \%(\mathrm{n}=4)$ \\
\hline
\end{tabular}

IV, intravenous.

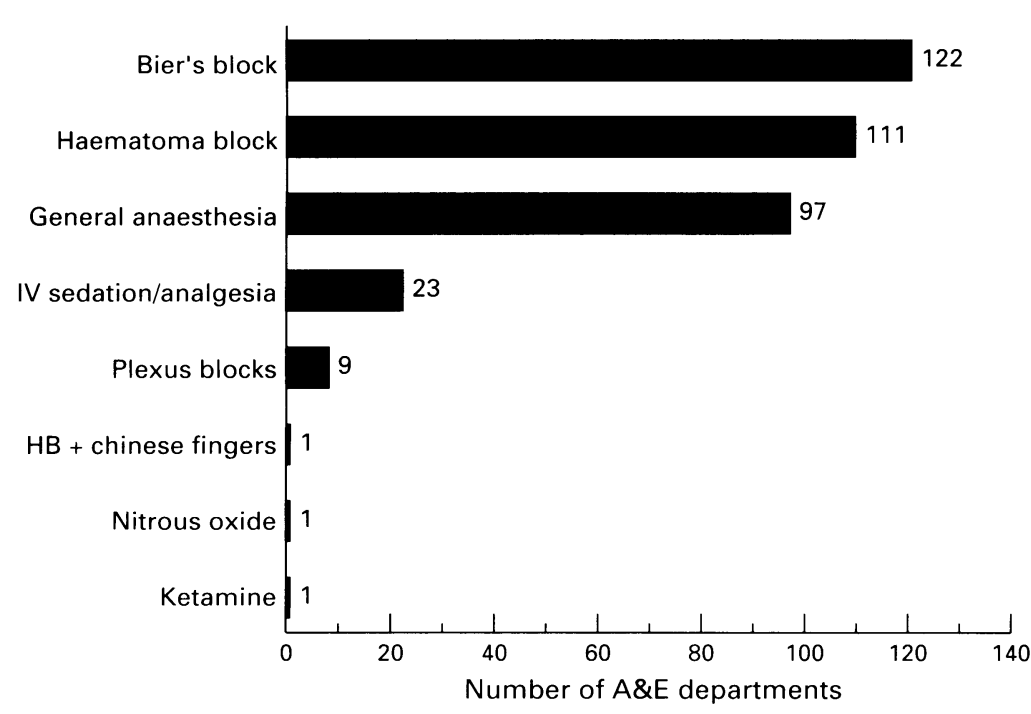

Figure 2 Types of analgesia
Table 2 Complications reported with Bier's block

\begin{tabular}{ll}
\hline Transient hypotension & 3 \\
"Fits" & 1 \\
Transient twitching & 1 \\
Vasovagal (emotional) presyncope & 1 \\
Radial nerve neuropraxia & 3 \\
Ulnar nerve neuropraxia & 1 \\
Cuff intolerance & 4 \\
Local swelling or bruising & 7 \\
\hline
\end{tabular}

fast (table 1). Complications were recorded in $22 \%$ of departments which did have a fasting policy, and in $14 \%$ of those that did not. None was related to inhalation problems.

Twenty one per cent of anaesthetic staff use additional sedation or analgesia, as do $12 \%$ of A\&E staff (table 1). Agents include opiates, benzodiazepines, mefenamic acid, and nitrous oxide.

Nineteen per cent of respondents noted complications at some time (table 2). Of these, two thirds were regarded as local or minor. No fatalities with prilocaine Bier's block were reported. Six complications occurred in units where A\&E staff give the IVRA. Twelve occurred where anaesthetists perform the block. Thus the relative complication risk was $22 \%$ when the prilocaine was given by anaesthetists and $14 \%$ when given by $\mathrm{A} \& \mathrm{E}$ staff. The incidence of potentially serious complications was similar in both groups.

Equipment failure was recorded in $19 \%$. Eighteen of these 23 replies mentioned some form of cuff leak.

\section{Discussion}

Bier's block is frequently employed in $\mathrm{A} / \mathrm{E}$ departments. It provides good analgesia and has the advantage of speedy progress and early discharge unless the patient is fasted. Haematoma block has been gaining popularity ${ }^{1}$ yet produces less analgesia ${ }^{2-4}$ and a less satisfactory anatomical result after fracture manipulation. ${ }^{2}$ Surprisingly, patients are often not fasted for haematoma blocks, ${ }^{5}$ yet potentially toxic systemic levels of local anaesthetic have been shown to occur during fracture manipulation under haematoma block. ${ }^{6}$

Prilocaine Bier's block is safe. ${ }^{134710}$ While minor systemic leaks of prilocaine may occur $^{11} 12$ and our study recorded 18 reported cuff leaks, no prilocaine associated deaths have ever been reported to the Committee on Safety of Medicines.

Some users ${ }^{13} 15$ advocate a strict starvation policy for Bier's block. Others ${ }^{16}{ }^{17}$ regard it as unnecessary and some ${ }^{1}$ question the need. Reasons cited for imposing starvation include possible pulmonary aspiration. Our study

confirmed that prilocaine Bier's block is safe
4 Hours $(26 \cdot 23 \%$

( $\mathrm{n}=23$ )

Figure 3 Fasting policies
2 Hours $(1.64 \%)$ $(n=2)$ 
and showed that non-fasting does not incur any increased risk of complications. Those complications which have been reported did not include any airway risk.

We found that $A \& E$ staff achieve similar analgesia yet are less likely to fast their patients than their anaesthetist colleagues. A\&E staff are also less likely to use supplemental sedation or analgesia and are less likely to experience complications. This may reflect the fact that the IVRA is usually performed by more senior $A \& E$ staff, who are more familiar with the procedure than the anaesthetic staff, who are often senior house officers new to the technique.

\section{CONCLUSION}

Prilocaine intravenous regional anaesthesia should be conducted by doctors experienced in the technique and in the recognition, prevention, and treatment of systemic local anaesthetic toxicity.

We believe that Bier's block is a safe procedure, to be carried out by experienced staff, without previous starvation of the patient.

We would like to thank all those who replied to our questionnaire and the audit department of Kent and Canterbury Hospital for their assistance.

1 Bartholomew K, Sloan JP. Prilocaine for Bier's block: how safe is safe? Arch Emerg Med 1990;7:189-95.
2 Abbaszadegan $\mathrm{H}$, Jonsson U. Regional anaesthesia preferable for Colles' fracture. Acta Orthop Scand 1990;61: 348-9.

3 Wardrope J, Flowers M, Wilson DH. Comparison of local anaesthetic techniques in the reduction of Colles' anaesthetic techniques in the reduction

4 Cobb AG, Houghton GR. Local anaesthetic infiltration versus Bier's block for Colles' fracture. BMF 1985; versus Bier's

5 Dinley RJ, Michelinakis E. Local anaesthesia in the reduction of Colles' fracture. Injury 1973;4:345-6.

6 Quinton DN. Local anaesthetic toxicity of haematoma blocks in manipulation of Colles' fractures. Injury 1988;19:239-40.

7 Wayne A, Colliza MD, Said E. Intravenous regional anaesthesia in the treatment of forearm and wrist fractures and dislocations in children. Can ₹ Surg 1993;36:225-8.

8 Pattison CW. A review of the Bier's block technique. Practitioner 1984;227:235-7.

9 Robinson DA, Shimmings KI. Uncomplicated accidental early tourniquet deflation during intravenous regional anaesthesia with prilocaine. Anaesthesia 1989;44:83-4.

10 Brown EM, McGriff JT, Malinowski RW. Intravenous regional anaesthesia; a review of 20 years experience. Can f Anaesth 1989;36:307-10.

11 Quinton DN, Hughes J, Mace PFK, Aithenhead AR. Prilocaine leakage during tourniquet inflation in intravenous regional anaesthesia: the influence of fracture manipulation. Injury 1988;19:333-5.

12 El-Hassen KM. Hurton P, Black AMS. Venous pressures and arm volume changes during simulated Bier's block. and arm volume changes durin

13 Steedman DJ, Payne MR, McClure JH, Prescott LF. Gastric emptying following Colles' fracture. Arch Emerg Med 1991:8:165-8.

14 Armstrong P, Payne M, Brockway M. Anaesthesia and Colles' fractures. BMF 1990;300:261.

15 Quinton DN. Regional anaesthesia for hand surgery in Accident and Emergency. Hosp Update 1989, November: 827-36.

16 Wallace $W$, Guardini $R$, Ellis S. Standard intravenous regional analgesia. $B M \mathcal{F}$ 1982;285:554-6.

7 Goold JE. Intravenous regional anaesthesia. Br f Hosp Med 1985 June: $335-40$ 